\title{
PENGARUH KONSENTRASI ASAM SULFAT DAN WAKTU HIDROLISIS TERHADAP KADAR ETANOL LIMBAH SERAT RUMBIASAGU (Metroxylon Sp) DAN SERAT SAGU BARUK(Arenga microcarpa)
}

\author{
THE EFFECT OF SULFURIC ACID CONCENTRATION AND HYDROLYSIS TIME \\ ETHANOL YIELD MADE FROM WASTE FIBER OF RUMBIA SAGO (METROXYLON \\ SP) AND BARUK SAGO (ARENGA MICROCARPA)
}

\author{
Sjamsiwarni R. Sjarif \\ Balai Riset dan Standardisasi Industri Manado \\ Jalan Diponegoro No.21-23 \\ Pos-el : reni sjarif@yahoo.co.id
}

Diterima Tanggal 27-10-2014, Disetujui Tanggal 10-11-2014

\begin{abstract}
ABSTRAK
Ampas sagu merupakan limbah yang dihasilkan dari pengolahan sagu terdiri dari seratserat empelur, kaya akan karbohidrat dan bahan organik lainnya. Pemanfaatan limbah sagu masih terbatas dan biasanya dibuang begitu saja. Penelitian ini bertujuan untuk memanfaatkan limbah serat sagu baruk dan sagu rumbia menjadi etanol dengan menggunakan metode deskriptif dilakukan dengan tiga tahap, yaitu: tahap pertama persiapan bahan baku dengan pengeringan, penggilingan dan pengayakan 4 dan 40 mesh. Tahap kedua hidrolisis dengan asam sulfat $0,5: 1,0$ dan $1,5 \mathrm{~N}$ waktu hidrolisa 2 , 3 dan 4 jam pada temperatur $121^{\circ} \mathrm{C}$ dengan autoclave dan fermentasi dengan ragi roti $3 \%$ selama 24 jam. Tahap ketiga destilasi alkohol. Pengamatan terlebih dahulu dilakukan terhadap kadar karbohidrat dan kadar gula bahan baku serat sagu baruk dan sagu rumbia, volume larutan hasil hidrolisis, kadar gula larutan hasil hidrolisis, volume destilat(etanol) dan kadar etanol. Hasil uji bahan baku menunjukkan kadar karbohidrat serat/ampas sagu baruk berkisar antara $41,22-49,18 \%$ dan sagu rumbia 52,78 $62,85 \%$. Kandungan gula yakni $1,91-3,19 \%$ untuk serat/ampas sagu baruk dan 1,28-3,19\% serat/ampas sagu rumbia. Hasil penelitian menunjukkan kadar gula tertinggi terdapat pada serat/ampas sagu rumbia dengan perlakuan penambahan asam sulfat 1,5 $\mathrm{N}$ dan waktu hidrolisis 3 jam yakni $13,90 \%$. Kadar etanol tertinggi juga diperoleh pada hasil fermentasi serat sagu rumbia yang diperlakukan dengan penambahan asam sulfat 1,0 N dan waktu hirolisa 3 jam hidrolisis $13,60 \%$. Limbah pengolahan pati sagu dari tanaman sagu (baruk dan rumbia) berupa serat/ampas dapat diolah menjadi etanol melalui proses hidrolisis asam sulfat konsentrasi rendah dengan pemanasan bertekanan.
\end{abstract}

Kata kunci : limbah serat sagu, etanol

\section{ABSTRACT}

Sago dregs, waste generated from sago processing, is rich in carbohydrates and other organic materials. Unfortunately, utilization of sago dregs is still limited and usually it is just thrown away. The aim of this research was to utilize sago baruk's and sago rumbia's dregs into ethanol. This research used descriptive method with three experiment steps. First, material preparation was done by drying, milling, and sieving the dregs at 4 and 40 mesh. Second, hydrolysis with sulfuric acid at $0.5 \mathrm{~N}, 1.0$, and $1.5 \mathrm{~N}$; hydrolysis time at 2, 3, and 4 hours; all treatment was done at $121^{\circ} \mathrm{C}$ at autoclave and 24 hours of fermentation with $3 \%$ yeast. Third, the distillation of alcohol. Prior observation was done to measure carbohydrate and sugar content in sago baruk's and sago rumbia's dregs, the volume of solution of hydrolysis, hydrolysis sugar solution, the volume of distillate (ethanol) and ethanol. Observation on the dregs showed that sago baruks has 41.22 to $49.18 \%$ of carbohydrate and $1.91 \%-3.19 \%$ of sugar; sago rumbia has $52.78 \%$ to $62.85 \%$ of carbohydrate and $1.28-3.19 \%$ of sugar. This research showed that the highest sugar content was obtained from Sago rumbia dregs which treated with addition of 1,5 N sulfuric acid with 3 hours of hydrolysis time. Moreover, the highest ethanol concentration was also obtained from Sago rumbia, treated with addition of $1.0 \mathrm{~N}$ 
sulfuric acid with 3 hours of hydrolysis time. Waste from sago starch processing can be utilize as ethanol through the addition of acid in low concentration with pressure heating.

Keywords: waste fiber sago, ethanol.

\section{PENDAHULUAN}

Salah satu kekayaan alam
Indonesia adalah tumbuhan sagu
(Metroxylon sp.). Luas areal tanaman sagu di Indonesia diperkirakan 1.114.000 hektar yang merupakan 50 persen dari total luas areal sagu dunia (1). Luas areal sagu yang sudah dibudidayakan baru sekitar 114.000 hektar, sedangkan lahan sagu seluas 1.000.000 hektar belum dibudidayakan secara intensif. Sagu dapat tumbuh di daerah rawa atau tanah marginal yang sulit ditumbuhi oleh tanaman penghasil karbohidrat lainnya (2). Selain sagu rumbia (Metroxylon Sp), di Sulawesi Utara terdapat pula sagu baruk (Arenga microcarpa). Sagu baruk dibudidayakan oleh masyarakat di kepulauan Sangihe.

Bioetanol dapat dibuat dari bahan nabati yang mengandung gula (nira, tebu, aren,molasses), pati (ubi jalar, ubi kayu,sorgum, jagung) atau lignoselulosa (jerami padi, tongkol jagung, tandan kosong kelapa sawit, bambu, kayu) (3).

Sagu memiliki kandungan pati yang besar. Menurut Haryanto dan Pangloli (2) pada umur panen sagu sekitar 11 tahun ke atas empulur sagu mengandung $15-20 \%$ pati. Proses ekstraksi pati sagu menghasilkan 3 jenis limbah, yaitu residu selular empulur sagu berserat (ampas), kulit batang sagu (bark), dan air buangan (wastewater).

Limbah ampas dan kulit batang sagu merupakan bahan lignoselulosa yang sebagian besar tersusun atas $22,45 \%$ selulosa, 11,8 hemiselulosa, 1,6\% senyawa ekstraktif dan 8,95\% lignin (4). Ampas sagu mempunyai kadar selulosa yang cukup tinggi. Selulosa ini dapat digunakan untuk pembuatan bioetanol dengan cara hidrolisa dan fermentasi (5).

Pada penelitian ini, menggunakan hidrolisa asam pekat untuk mengubah selulosa dalam ampas tebu menjadi glukosa reduksi.

Selulosa ini dapat di merupakan limbah yang dihasilkan dari pengolahan sagu, kaya akan karbohidrat dan bahan organik lainnya. Pemanfaatannya masih terbatas dan biasanya dibuang begitu saja ketempat penampungan atau kesungai yang ada disekitar daerah penghasil. Oleh karena itu ampas sagu berpotensi menimbulkan dampak pencemaran lingkungan, karena melihat kandungan dari limbah ampas/ serat sagu maka dapat diolah menjadi bioetanol sebagai bahan bakar alternatif melalui proses hidrolisis dengan asam pada temperature $121^{\circ} \mathrm{C}$..

Etanol merupakan salah satu sumber energi alternatif yang mempunyai beberapa kelebihan, diantaranya sifat etanol yang dapat diperbarui dan ramah lingkungan karena emisi karbondioksidanya rendah (6).

Proses yang digunakan untuk mendapatkan produk bioetanol dilakukan dengan variasi waktu dan dosis $\mathrm{H} 2 \mathrm{SO} 4$ yang berbeda untuk dapat mengetahui pengaruhnya terhadap kadar etanol yang dihasilkan. Banyaknya bioetanol yang 
dihasilkan tergantung dari waktu, semakin lama waktu hidrolisa, maka semakin banyak jumlah etanol yang dihasilkan. Untuk dosis $\mathrm{H} 2 \mathrm{SO} 4$ encer, semakin tinggi temperatur dan lama waktu hidrolisa, maka semakin tinggi kadar etanol yang diperoleh, dan sebaliknya untuk H2SO4 pekat (7).

\section{BAHAN DAN METODE}

\section{Bahan dan Alat}

Bahan-bahan yang digunakan dalam penelitian ini yaitu ampas/serat sagu baruk diperoleh dari kepulauan Sangihe dan sagu rumbia diperoleh dari kepulauan Talaud, asam sulfat, natrium hidroksida, ragi roti fermipan, dan bahan kimia untuk analisis. Peralatan yang digunakan dalam penelitian yaitu autoklaf, alat penghancur serat (dish mill), fermentor, alat suling, kompor, Erlenmeyer, gelas piala, hand refraktometer, piknometer, alkohol meter, $\mathrm{pH}$ meter, neraca, oven dan kertas saring.

\section{Metode Penelitian}

Penelitian ini menggunakan metode deskritif dilaksanakan dalam tiga tahap, tahap pertama persiapan bahan baku, tahap kedua hidrolisis dan fermentasi dan tahap tiga yaitu destilasi etanol. Penelitan dilakukan dengan 2 kali pengulangan dan dilakukan pengamatan terhadap kadar gula dan etanol.

\section{Tahapan Pekerjaan}

\section{Persiapan Bahan Baku}

Pada tahap ini bahan ampas sagu kering diperlakukan penggilingan dengan tujuan untuk mencari tingkat kehalusan bahan baku yang akan diproses sehingga didapatkan kadar karbohidrat dan kadar gula tertinggi. Adapun tingkat kehalusan yang diperlakukan yakni 4 dan 40 mesh. Hasil perlakuan terbaik tahap 1 menjadi dasar untuk penelitian selanjutnya.

\section{Hidrolisis dan fermentasi}

Pada tahap ini dilakukan untuk melihat pengaruh penambahan asam sulfat dengan beberapa konsentrasi yakni 0,5, 1,0 dan 1,5 $\mathrm{N}$, hidrolisis dengan autoclaf suhu $121^{\circ} \mathrm{C}$ tekanan $76 \mathrm{cmHg}$ serta waktu hidrolisis 2 , 3 , dan 4 jam. Fermentasi pada suhu $37^{\circ} \mathrm{C}$ dengan ragi roti $3 \%$ selama 24 jam.

Tahap 3. Destilasi etanol

Pada tahap ini dilakukan destilasi alkohol untuk mendapatkan kadar etanol tertinggi dari hasil perlakuan pada tahap dua.

\section{Prosedur Penelitian}

Serat sagu dipisahkan dari kotoran/benda bukan serat sagu kemudian Serat sagu dihaluskan dengan menggunakan dish mill , dilakukan uji karbohidrat, gula. Ditimbang serat sagu $75,0 \mathrm{~g}$ lalu ditambahkan $750 \mathrm{~mL}$ larutan asam sulfat $(0,5: 1,0: 1,5 \mathrm{~N})$ dalam Erlenmeyer $1000 \mathrm{~mL}$. Serat sagu berisi asam sulfat dimasukkan kedalam autoclave dan dipanaskan pada suhu $121{ }^{\circ} \mathrm{C}$ waktu (2,3 dan 4 jam) dengan tekanan $76 \mathrm{cmHg}$ untuk proses hidrolisis, kemudian hasil hidrolisis dinetralkan dengan larutan $\mathrm{NaOH}$ $2 \%$ hingga $\mathrm{pH} 5$, lalu diukur volume larutan/hidrolisat dan dilakukan uji kadar gula. Polisakarida pada umumnya berupa senyawa putih dan tidak berasa manis (8). Beberapa polisakarida dapat larut dalam air. Contoh : glikogen,pati,amilum,selulosa. Serat sagu mengandung pati dan selulosa. 
Uji kadar gula total dengan metode luff schrool.

Luff schrool merupakan salah satu metode yang dapat digunakan dalam penentuan kadar karbohidrat secara kimiawi untuk menetapkan kadar glukosa pada berbagai jenis cairan yang mengandung gula.

Larutan/ Hidrolisat disaring lalu ditambahkan ragi roti (Fermipan) 3\%,

Diagram alir proses pembuatan etanol dari limbah serat/ampas sagu tercantum pada Gambar 1 di bawah ini. kemudian Medium fermentasi ditutup dengan kertas kraft dan dimasukkan kedalam fermentor selama 24 jam. Setelah 24 jam, Larutan/cairan hasil fermentasi dilakukan penyulingan/destilasi untuk memisahkan air dan etanol, kadar etanol diuji dengan piknometer dan rendemennya ditentukan.

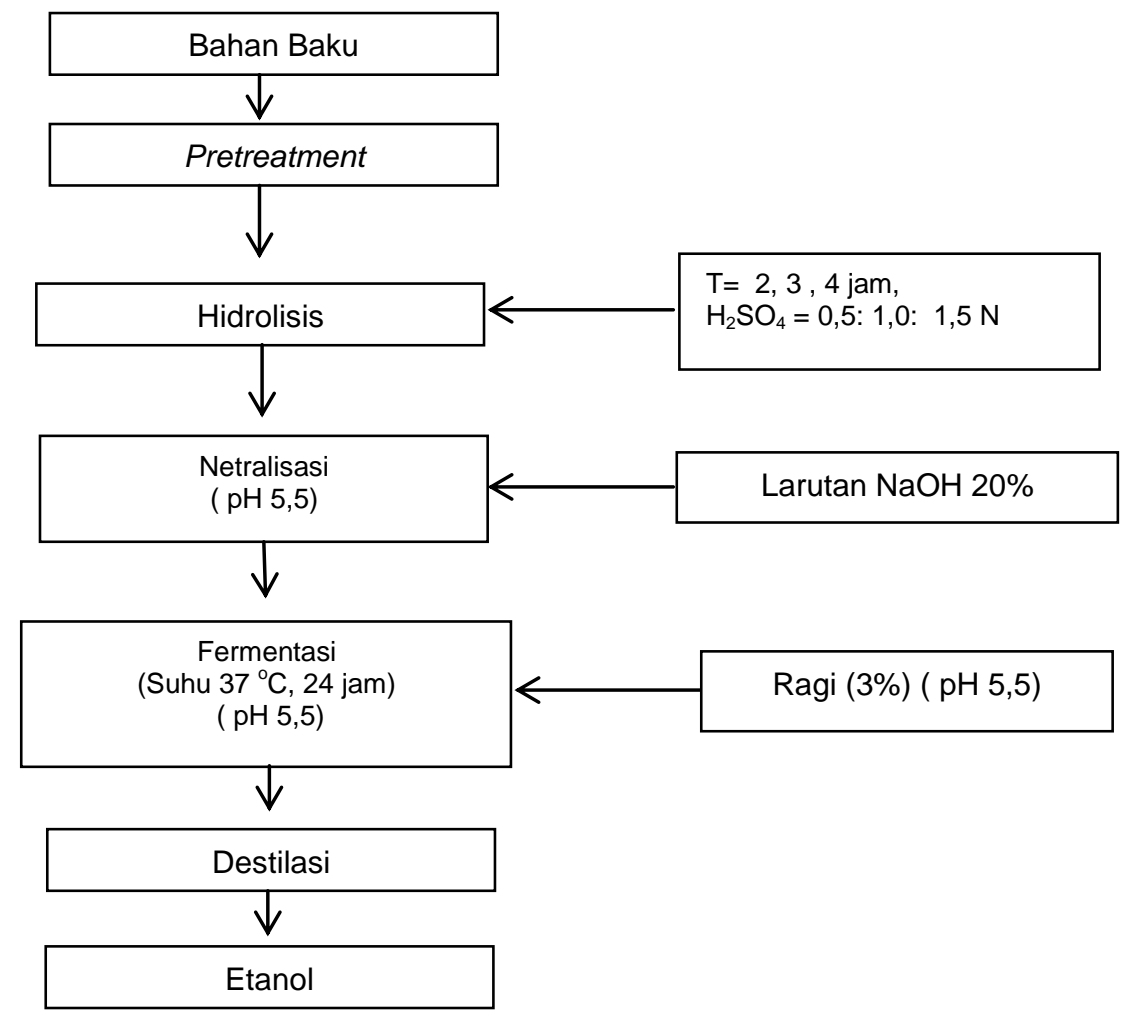

Gambar 1. Diagram alir pembuatan etanol dari ampas/serat sagu

\section{HASIL DAN PEMBAHASAN}

\section{Kadar Karbohidrat dan Gula Serat Sagu}

Hasil uji kadar karbohidrat dan kadar gula dengan berbagai ukuran kehalusan serat sagu tercantum pada Tabel 1 di bawah ini.

Hasil analisis kadar karbohidrat dan gula dengan 2 jenis serat sagu yaitu sagu baruk dan sagu rumbia dengan ukuran kasar 4 
mesh dan ukuran serat halus 40 mesh menunjukkan bahwa jenis serat sagu dan ukuran kehalusan serat sagu memberikan perbedaan hasil terhadap kadar karbohidrat dan kadar gula. Kadar karbohidrat tertinggi diperoleh pada serat sagu rumbia dengan kehalusan 40 mesh yakni $62,85 \%$, sedangkan kadar karbohidrat terendah pada serat sagu baruk yaitu $41,22 \%$. Sebaliknya untuk kadar gula ternyata serat sagu baruk cenderung lebih tinggi dibandingkan serat sagu rumbia pada ukuran kehalusan kasar (4 mesh) yakni $1,91 \%$ (sagu baruk) dan 1,28\% (sagu rumbia). Akan tetapi pada kehalusan serat 40 mesh kadar gula kedua jenis serat ini sama yakni $3,19 \%$.

Tabel 1. Hasil uji kadar karbohidrat dan Gula

\begin{tabular}{ccccc}
\hline No. & Jenis Serat Sagu & Ukuran serat & Karbohidrat (\%) & Gula (\%) \\
\hline 1 & Sagu Baruk & Kasar (4 mesh) & 41,22 & 1,91 \\
2 & Sagu Baruk & Halus (40 mesh) & 49,18 & 3,19 \\
3 & Sagu Rumbia & Kasar (4 mesh) & 52,78 & 1,28 \\
4 & Sagu Rumbia & Halus (40 mesh) & 62,85 & 3,19 \\
\hline
\end{tabular}

Tingginya kadar karbohidrat pada serat sagu rumbia dipengaruhi oleh beberapa faktor diantaranya adanya pati (karbohidrat) yang tidak terekstrak ketika proses ekstraksi sagu dan tertinggal pada serat/empulur sagu (limbah), hal ini dapat terjadi karena proses ekstraksi dari serat/empulur sagu rumbia dilakukan secara tradisionil (contoh dari proses ekstraksi/pencucian menggunakan tangan manusia). Pada proses ekstraksi sagu baruk menggunakan alat mesin ekstraksi dan diduga karena menggunakan mesin, maka proses ekstraksi/pencucian pati dalam serat lebih maksimal juga alat bekerja secara kontinu sehingga pati (karbohidrat yang tertinggal dalam serat sagu baruk sedikit).

Kadar gula serat sagu baruk dan serat rumbia cenderung berbeda pada ukuran serat ( ukuran 4 mesh) akan tetapi sama pada kehalusan 40 mesh. Adanya perbedaan kadar gula pada ukuran serat kasar (4 mesh) dipengaruhi oleh beberapa faktor antara lain pada serat yang halus ( 40 mesh) proses hidrolisis karbohidrat menjadi gula sederhana labih mudah karena penetrasi asam ( $\mathrm{H} 2 \mathrm{SO} 4)$ kedalam butiran/serbuk serat lebih maksimal dibandingkan denga keadaan serat yang kasar dan dengan sendirinya proses perubahan karbohidrat menjadi gula akan maksimal, sebaliknya pada ukuran luas permukaan serat kasar (butiran kasar) penetrasi asam kedalam serat tidak maksimal karena diameter serat yang besar dan diduga tidak semua bagian serat di penetrasi oleh asam yang akan merubah karbohidrat menjadi gula sederhana.

Berdasarkan hasil uji terhadap kadar karbohidrat dan gula serat sagu dengan berbagai ukuran dan ternyata serat yang dihaluskan sampai dengan 40 mesh 
memberikan kadar tertinggi, maka untuk perlakuan selanjutnya menggunakan serat sagu dengan ukluran 40 mesh.

Volume awal $750 \mathrm{~mL}$ (asam sulfat yang ditambahkan pada $75 \mathrm{~g}$ contoh serat sagu) setelah melalui proses hidrolisis dan penetralan dengan larutan $\mathrm{NaOH}$ serta penyaringan, maka volume akhir larutan tidak sama dengan volume awal tapi berkisar antara $600 \mathrm{~mL}-700 \mathrm{~mL}$, begitu pula untuk berat contoh $25 \mathrm{~g}$ dengan penambahan asam sulfat $250 \mathrm{~mL}$, volume akhir dibawah volume awal yaitu antara 240 $\mathrm{mL}-245 \mathrm{~mL}$.

Hasil ini menunjukkan bahwa ada pengurangan volume ekstrak cairan yang dihasilkan dibandingkan dengan volume awal larutan sebelum proses hidrolisis.
Adanya pengurangan volume larutan/cairan pada akhir proses disebabkan oleh antara lain sebagian larutan tertinggal dalam butiran serat sagu dan tidak ikut tersaring kedalam larutan ekstrak ini ditandai dengan butiran serat sagu tetap basah setelah dibiarkan 2 jam setelah proses penyaringan juga sebagian cairan melekat pada kertas saring.

\section{Pengaruh Konsentrasi Asam dan Waktu Hidrolisis Terhadap Kadar Gula Serat Sagu}

Setelah melalui proses hidrolisis dengan penambahan asam sulfat 0,$5 ; 1,0$ dan 1,5 $\mathrm{N}$ serta waktu hidrolisis yang bervariasi, maka diperoleh kadar gula serat sagu seperti tercantum pada Gambar 1.

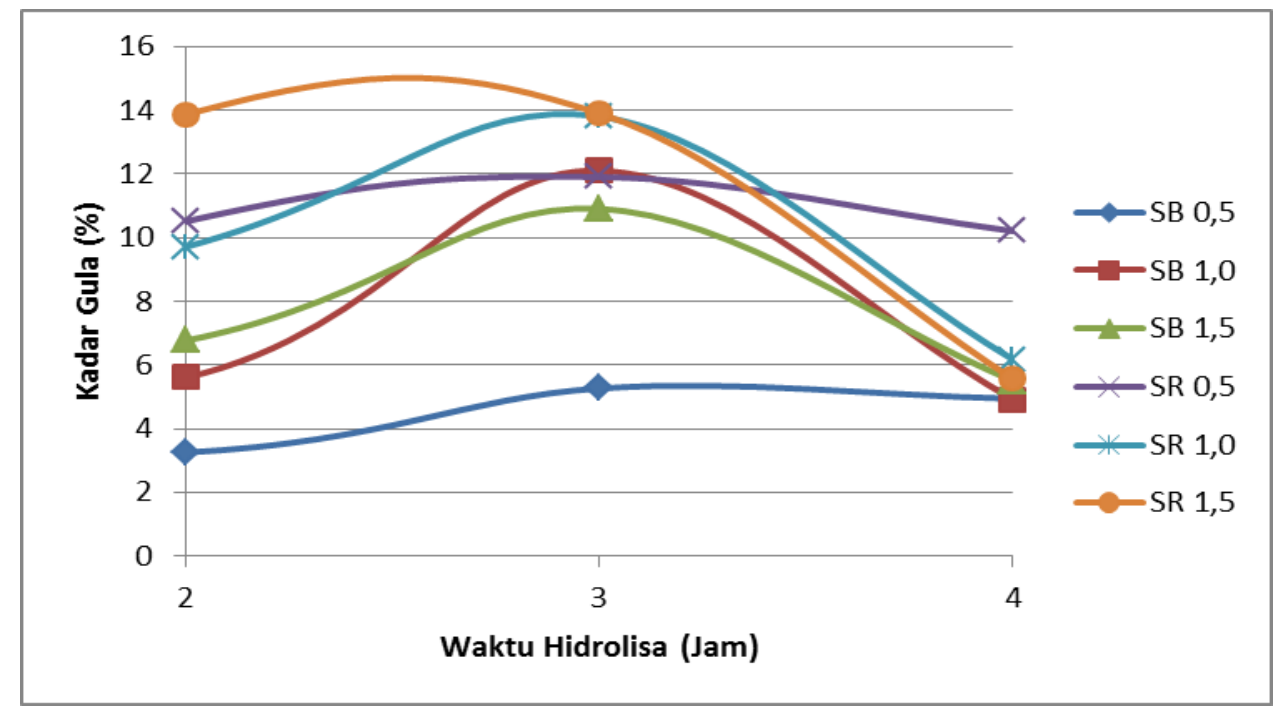

Ket : SB (Sagu Baruk) dengan konsentrasi asam sulfat 0,$5 ; 1,0$ dan $1,5 \mathrm{~N}$

SR (Sagu Rumbia) dengan konsentrasi asam sulfat 0,$5 ; 1,0$ dan 1,5 N

Gambar 1. Pengaruh konsentrasi Asam Sulfat dan Waktu Hidrolisis Terhadap Kadar Gula Serat Sagu

Pembuatan etanol dari bahan baku

limbah serat/empulur sagu akan dipengaruhi oleh berbagai faktor, dan untuk mendapatkan hasil yang optimal, maka salah satu faktor yang sangat berpengaruh dalam proses hidrolisis ialah konsentrasi asam. Penggunaan asam dengan konsentrasi tinggi atau konsentrasi rendah 
akan memberikan hasil yang bervariasi.

Beberapa peneliti Hamelinck, et al (9) menyatakan bahwa penggunaan asam dengan konsentrasi tinggi akan memberikan kadar gula yang tinggi setelah melalui tahapan hidrolisis, namun mempunyai kelemahan dari segi biaya dan lingkungan. Sebaliknya peneliti lain De Idral (10) menyatakan bahwa penggunaan asam sulfat dengan konsentrasi rendah $(0,3 \mathrm{~N})$ akan memberikan hasil optimal. Penggunaan asam sulfat konsentrasi rendah juga menghemat biaya karena ongkos produksi lebih rendah dan murah serta dampak terhadap lingkungan tidak seberat jika mengunakan asam sulfat dengan konsentrasi tinggi. Selain faktor konsentrasi asam sulfat, maka faktor waktu hidrolisis terhadap serat selulosa mempengaruhi kadar gula yang dihasilkan, hasil penelitian Polii (11) terhadap waktu hidrolisis terhadap serat selulosa sabut kelapa menunjukkan semakin lama waktu hidrolisis (6 jam), maka kadar gula yang dihasilkan akan semakin tinggi. Akan tetapi peneliti lain De Idral (10) menyatakan bahwa pada waktu hidrolisis 2 jam dihasilkan kadar gula optimal (tertinggi) dan jika hidrolisis dilakukan di atas 2 jam (120 menit), maka kadar gula yang dihasilkan cenderung menurun Untuk mendapatkan hasil optimal dalam proses hidrolisis serat sagu khususnya jumlah gula, maka telah dilakukan penelitian penggunaan asam sulfat dengan konsentrasi rendah yaitu 0,5 ; 1,$0 ; 1,5 \mathrm{~N}$ dan divariasikan dengan waktu hidrolisis yakni 2,3 dan 4 jam. Hasil penelitian dengan perlakuan penggunaan asam sulfat berbagai konsentrasi dan waktu hidrolisis menunjukkan pada penggunaan konsentrasi asam sulfat $0,5 \mathrm{~N}$ dan waktu hidrolisis 2 jam baik serat sagu baruk maupun serat sagu rumbia menghasilkan kadar gula rendah $(3,25 \%$ dan $10,50 \%)$, akan tetapi dengan meningkatnya konsentrasi asam sulfat serta waktu hidrolisis sewaktu 3 jam kadar gula yang dihasilkan mencapai angka maksimal /optimal $(12,10 \%$ serat sagu baruk dan 13,90 serat sagu rumbia) dan pada proses hidrolisis 4 jam kadar gula yang di hasilkan mulai menurun $(4,92 \%$ serat sagu baruk dan $5,56 \%$ serat sagu rumbia) dari grafik 1. diatas menunjukkan kadar gula tertinggi hasil hidrolisis diperoleh pada konsentrasi asam sulfat $1,5 \mathrm{~N}$ yakni $13,90 \%$ (serat sagu rumbia). Tingginya kadar gula yang diperoleh pada hidrolisis asam sulfat $1,5 \mathrm{~N}$ terjadi karena pada konsentrasi asam sulfat $1,5 \mathrm{~N}$, proses degradasi/peruraian selulosa (alfa selulosa dan hemiselulosa) serat sagu optimal, dimana komponen asam dapat secara optimal memutuskan rantai ikatan alfa maupun beta selulosa sehingga terputus/terurai menjadi monomermonomer gula tunggal yakni glukosa (selulosa tersusun oleh monosakarida diantaranya glukosa dengan ikatan alfa dan beta). Pada konsentrasi asam sulfat 0,5 N hidrolisis tidak berlangsung optimal karena kadar gula relatif rendah. Hal ini diduga asam belum optimal atau tidak cukup untuk menguraikan/memutuskan ikatan alfa dan beta glukosa pada serat sagu, disamping itu konsentrasi asam yang kurang tidak mempu memecahkan komponen lain yang merekatkan antar selulosa maupun lignin 
yang menyatukan sel selulosa yang satu dengan yang lain. Pada konsentrasi larutan asam sulfat $1,5 \mathrm{~N}$ dalam proses hidrolisis gugus $\mathrm{H}^{+}$dari asam akan mengubah gugus serat sagu menjadi gugus radikal bebas dan gugus radikal bebas serat sagu yang kemudian akan berikatan dengan gugus $\mathrm{OH}^{-}$dari air dan bereaksi pada suhu 120 ${ }^{\circ} \mathrm{C}$ (suhu autoclave) menghasilkan gula tinggi, sebaliknya pada konsentrasi asam sulfat rendah $(0,5$ dan $1,0 \mathrm{~N})$ kebutuhan $\mathrm{H}^{+}$ dari asam belum mencukupi sehingga tidak banyak terbentuk radikal bebas dari serat sagu dan gula yang dihasilkan belum maksimal.Pada hidrolisis 3 jam merupakan waktu optimal terjadinya hidrolisis, dimana selulosa yang ada dalam serat sagu semakin waktu bersentuhan dengan asam yang ditambahkan juga proses dekomposisi selulosa terurai menjadi karbohidrat (gula) semakin banyak. Faktor lain yaitu suhu bertekanan yang dilakukan dalam jangka waktu yang optimum pada proses hidrolisis sangat berpengaruh terhadap perombakan bahan-bahan yang melindungi atau mengikat komponen selulosa dalam serat menjadi monosakarida-monosakarida bebas yang tidak terikat baik alfa maupun beta glukosa.

\section{Rendemen}

Hasil pengamatan perhitungan rendemen etanol (Gambar 2) terlihat bahwa rendemen etanol yang dihasilkan berkisar antara $32,85 \%-81,63$, rendemen tertinggi diperoleh pada sagu baruk proses hidrolisis 4 jam dengan penambahan larutan asam sulfat $1,5 \mathrm{~N}$ dan terendah pada sagu rumbia perlakuan penambahan asam sulfat 1,0 N dan waktu hidrolisis 2 jam. Gambar 2.diatas juga menunjukkan semakin tinggi konsentrasi larutan asam sulfat yang ditambahkan dan semakin lama waktu hidrolisis, maka rendeman etanol/bioetanol yang dihasilkan semakin tinggi. Hal ini terjadi karena pada awal destilasi volume larutan yang dihidrolisis dengan konsentrasi asam sulfat tinggi relatif lebih tinggi daripada volume larutan awal cairan yang diproses dengan asam sulfat konsentrasi rendah (perlakuan 2 dan 3 jam waktu hidrolisis).

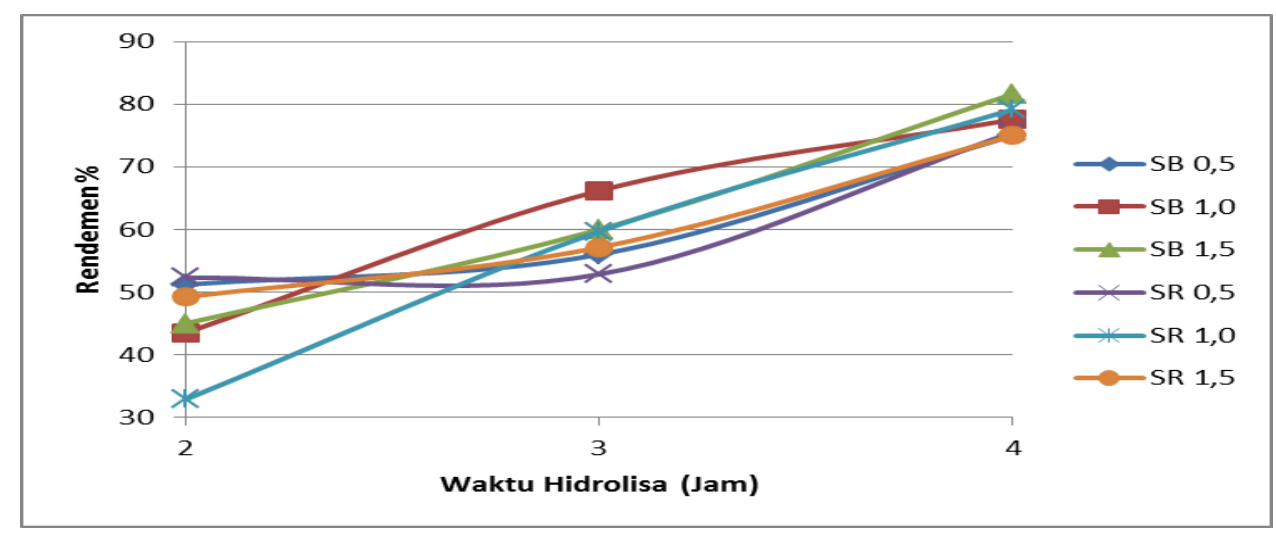

Ket : SB (Sagu Baruk) dengan konsentrasi $\mathrm{H}_{2} \mathrm{SO}_{4} \quad 0,5 ; 1,0$ dan $1,5 \mathrm{~N}$ $\mathrm{SR}$ (Sagu Rumbia) dengan konsentrasi $\mathrm{H}_{2} \mathrm{SO}_{4} \quad 0,5 ; 1,0$ dan $1,5 \mathrm{~N}$

Gambar 2. Pengamatan Rendemen Etanol 
Tinggi atau rendahnya persentase rendemen larutan etanol yang dihasilkan ditentukan oleh sistem pemanasan pada tahap penyulingan dan waktu proses destilasi. Semakin tinggi suhu pemanasan dan semakin lama proses destilasi, maka semakin banyak rendemen yang diperoleh, sebaliknya semakin rendah suhu pemanasan dan waktu penyulingan yang tidak lama, maka rendemen yang di hasilkan relative rendah. Dalam proses destilasi etanol, faktor suhu sangat berperan, agar hasil destilasi etanol optimal, maka sewaktu proses destilasi diusahakan agar suhu minimum dan sebaiknya suhu dibawah $100^{\circ} \mathrm{C}$.

\section{Fermentasi Gula Menjadi Etanol}

Proses perobahan/fermentasi etanol/bioetanol dari gula hasil hidrolisis serat sagu oleh ragi menjdi etanol,angka kuantitatif tercantum pada Gambar 3.

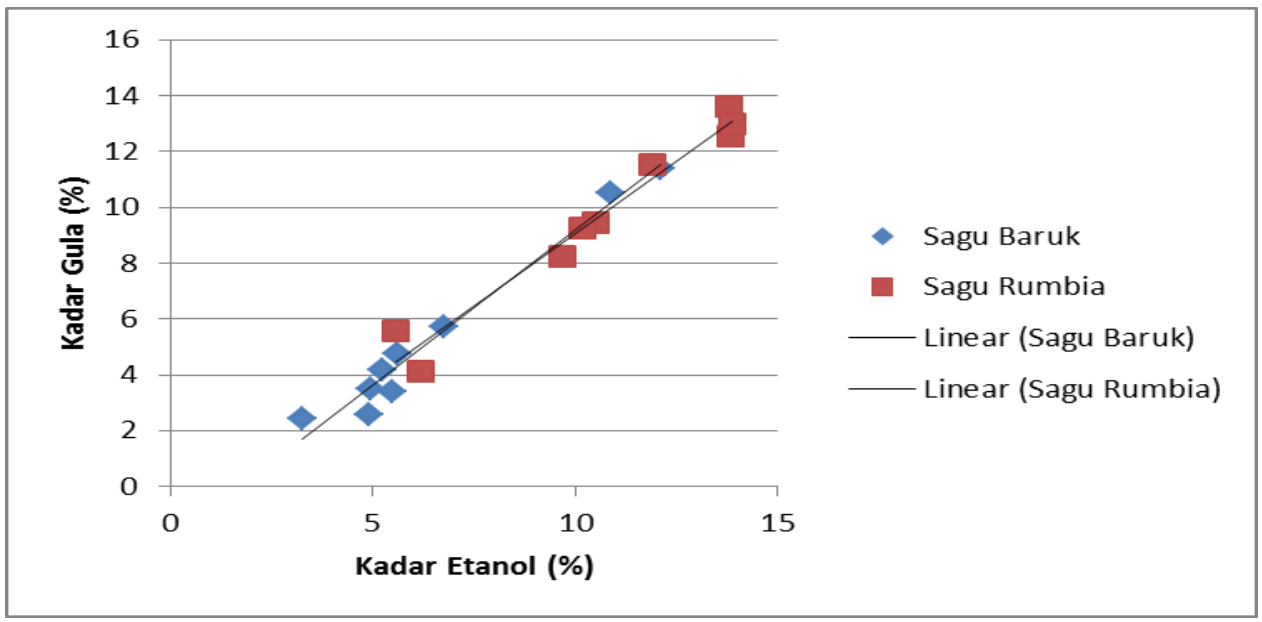

Gambar. 3 Pengaruh Kadar Gula Menjadi Etanol

Pada Gambar. 3 menunjukkan kadar etanol tertinggi yakni $13,60 \%$, pada penambahan larutan asam sulfat 1,0 N dan waktu hidrolisis 3 jam, sedangkan kadar ertanol terendah pada proses penambahan larutan asam sulfat $0,5 \mathrm{~N}$ dan waktu hidrolisis 2 jam yaitu 2,43\%. Kadar etanol meningkat seiring dengan kenaikkan persentase kadar gula, semakin tinggi kadar gula serat sagu hasil hidrolisis, maka semakin tinggi kandungan etanol yang diperoleh setelah proses fermentasi oleh ragi. Gambar diatas memperlihatkan apabila kadar gula dalam larutan serat sagu di atas $10 \%$, maka mikroorganisme khamir (ragi) akan optimal melakukan fermentasi/merubah gula menjadi etanol, bahkan angka persentasenya di atas $90 \%$, sebaliknya jika kandungan gula dalam larutan serat sagu di bawah 10\% ternyata mikroorganisme tidak optimal merombak gula menjadi etanol dan angka persentase keberhasilan fermentasi di bawah $90 \%$.

Keberhasilan mikroorganisme khamir dalam melakukan fermentasi gula menjadi etanol dipengaruhi oleh berbagai faktor antara lain $\mathrm{pH}$ larutan dan ketersediaan nutrien. Pada larutan hasil hidrolisis serat 
sagu dengan kandungan gula tinggi juga ketersediaan nutrisi tinggi sehingga hampir semua khamir/ragi yang ditambahkan melakukan aktifitas fermentasi merubah gula menjadi etanol dan dengan demikian kadar etanol tinggi. Sebaliknya apabila kadar gula dalam larutan hasil hidrolisis serat sagu rendah, maka kandungan nutrisi dalam larutan tersebut rendah mengakibatkan ada sebagian ragi tidak mendapatkan makanan/nutrisi untuk merubah gula menjadi alkohol bahkan sebagian mikroorganisme akan mengubah etanol menjadi asam asetat dan mengakibatkan penurunan kadar etanol.

\section{KESIMPULAN}

Ampas sagu baruk dan sagu rumbia dapat diolah menjadi etanol.Kadar alkohol yang diperoleh dari limbah serat sagu baruk berkisar 2,43-11,36\% dan pada ampas sagu rumbia berkisar 4,13-13,60\%. Kadar gula tertnggi diperoleh pada ampas sagu rumbia dengan penambahan asam sulfat $1 \mathrm{~N}$ dan waktu hidrolisa 3 jam yakni $13,90 \%$. Kadar alkohol tertinggi juga terdapat pada ampas sagu rumbia dengan penambahan asam sulfat $1 \mathrm{~N}$ dan waktu hidrolisis 3 jam yaitu $13,60 \%$.

\section{DAFTAR PUSTAKA}

1. Abner L M. Keragaan Industri Sagu Indonesia. Warta Penelitian dan Pengembangan Tanaman Industri. Vol. 8 No. 1 Juni 2002; 2002;

2. Haryanto B PP. Potensi dan Pemanfaatan Sagu. Kanisius; 1992.
3. Komaryati. S G. Prospek Bioetanol Sebagai Pengganti Minyak Tanah Pusat Penelitian dan Pengembangan Hasil Hutan. 2010.

4. Hisyam. Isolasi Selulosa Ampas Sagu dengan Delignifikasi Menggunakan Hidrogen Peroksida. Institut Pertanian Bogor; 2012.

5. Enny. K Artati. Konstanta Kecepatan Reaksi Sebagai Fungsi Suhu Pada Hidrolisa Selulosa dari Ampas Tebu dengan Katalisator Asam Sulfat. Ekuilibrium. 2010; Vol. 9 No (14129124).

6. Jeon BY et al. Development Of a Serial Bioreactor System For Direct Ethanol Production From Starch Using Aspergillus Niger and Saccharomyces Cerevisiae. Biotechnol Bioprocess Eng. 2007; Vol. 12:566-73.

7. Ramdja Fuadi D. Pengaruh Waktu, Temperatur dan Dosis H2SO4 Pada Hidrolisa Asam Terhadap Kadar Etanol Berbahan Baku Alang-Alang. J Tek. Vol. 17 No.

8. Fitriyana L. Analisis Kadar Bioetanol Hasil Fermentasi Dari Pati Sagu (Metroxylon sago) Asal Papua. Universitas Negeri Papua; 2009.

9. Hamelinck, CN VHG dan FA. Prospect For Ethanol From Lignocellulosic Biomass. Netherlands; 2005.

10. Daniel dkk. Pembuatan Bioetanol dari Ampas Sagu dengan Proses Hidrolisa 
Asam dan Saccharomyces Cerevisiae.

J Kim Unand. Volume $1 \mathrm{~N}$.

11. Polii F F. Pengembangan Paket

Teknologi Tepat Guna Etanol dari

Limbah Pertanian Berlignoselulosa.

Manado; 2009. 
